\title{
Markers of adipose tissue hypoxia are elevated in subcutaneous adipose tissue of severely obese patients with obesity hypoventilation syndrome but not in the moderately obese
}

\author{
Marijana Todorčević $^{1}$ - Ari R. Manuel ${ }^{2,3} \cdot$ Luke Austen $^{1} \cdot$ Zoi Michailidou $^{4} \cdot$ Jonathan M. Hazlehurst $^{1,5}$. \\ Matt Neville $\mathbb{I}^{1} \cdot$ John R. Stradling ${ }^{2,6} \cdot$ Fredrik Karpe $\mathbb{i}^{1,6}$
}

Received: 24 August 2020 / Revised: 1 February 2021 / Accepted: 11 February 2021 / Published online: 23 March 2021

(c) The Author(s) 2021. This article is published with open access

\begin{abstract}
It has been suggested that metabolic dysfunction in obesity is at least in part driven by adipose tissue (AT) hypoxia. However, studies on AT hypoxia in humans have shown conflicting data. Therefore we aimed to investigate if markers of AT hypoxia were present in the subcutaneous AT of severly obese individuals (class III obesity) with and without hypoventilation syndrome (OHS) in comparison to moderately obese (class I obesity) and lean controls. To provide a proofof-concept study, we quantified AT hypoxia by hypoxia inducible factor $1 \mathrm{~A}$ (HIF1A) protein abundance in human participants ranging from lean to severly obese (class III obesity). On top of that nightly arterial $\mathrm{O}_{2}$ saturation in individuals with obesity OHS was assessed. Subjects with class III obesity (BMI $>40 \mathrm{~kg} / \mathrm{m}^{2}$ ) and OHS exhibited significantly higher adipose HIF1A protein levels versus those with class I obesity (BMI $30-34.9 \mathrm{~kg} / \mathrm{m}^{2}$ ) and lean controls whereas those with class III obesity without OHS showed an intermediate response. HIFIA gene expression was not well correlated with protein abundance. Although these data demonstrate genuine AT hypoxia in the expected pathophysiological context of OHS, we did not observe a hypoxia signal in lesser degrees of obesity suggesting that adipose dysfunction may not be driven by hypoxia in moderate obesity.
\end{abstract}

\section{Introduction}

Although tissue hypoxia can be caused by low oxygen delivery, it can be augmented by high oxygen

Fredrik Karpe

fredrik.karpe@ocdem.ox.ac.uk

1 Oxford Centre for Diabetes, Endocrinology and Metabolism, Radcliffe Department of Medicine, University of Oxford, Oxford, UK

2 Oxford Respiratory Trials Unit, Churchill Hospital, University of Oxford, Oxford, UK

3 Liverpool Centre for Respiratory Science, University of Liverpool, Liverpool, UK

4 Queen's Medical Research, Institute Centre for Cardiovascular Research, University of Edinburgh, Edinburgh, UK

5 Institute of Metabolism and Systems Research, University of Birmingham, Birmingham, UK

6 NIHR Oxford Biomedical Research Centre, OUH Trust, Churchill Hospital, Oxford, UK consumption. A general feature of human white AT is its low oxygen consumption, a high degree of glycolysis and a respiratory quotient close to 1.0 , indicating a near absence of $\mathrm{O}_{2}$-consuming fatty acid oxidation [1]. However, there may well be species differences as artificially reducing the tissue oxygen consumption in mice, through adipose-specific ablation of adenine nucleotide translocase 2 (ablates mitochondrial fatty acid oxidation) preserves higher oxygen tension in AT with normalised whole body metabolic function [2].

Methods to verify hypoxia in AT is in vivo include staining with pimonidazole, detection of HIF1A protein induction or direct monitoring oxygen tension in situ. However, these approaches have given rise to conflicting data with signs of AT hypoxia [3] or increased [4] $\mathrm{O}_{2}$ tension. Therefore, in order to further evaluate the presence of hypoxia in human AT, we assembled participants with a wide range of body fatness, also including a subgroup with obesity hypoventilation syndrome (OHS). The presence of HIF1A protein in AT biopsies together with downstream transcriptional targets of HIF1A were taken as indicators of tissue hypoxia. 


\section{Methods}

\section{Subcutaneous abdominal adipose biopsies from patients of different levels of adiposity with and without OHS}

Eight lean (mean BMI $24.2 \mathrm{~kg} / \mathrm{m}^{2}$, six men) and 8 class I obese (mean BMI $32.5 \mathrm{~kg} / \mathrm{m}^{2}$, six men) healthy participants were recruited from the Oxford Biobank [5]. Subcutaneous AT biopsies were taken under local anaesthesia using a liposuction method first thing in the morning and immediately snap frozen in liquid $\mathrm{N}_{2}$. Two further groups ( $n=9$, six men in each group) of class III obese patients with or without OHS (both groups with mean BMI of $45.3 \mathrm{~kg} / \mathrm{m}^{2}$ ) were identified from a previous study [6] but from the same geographic and demographic region as the Oxford Biobank, and provided a biopsy using the same technique. None of the participants had a formal diagnosis of type 2 diabetes. The lean and class I obese groups were not monitored overnight with pulse oximetry $\left(\mathrm{SpO}_{2}\right)$ but were questioned of symptoms related to OHS, which were negated. The class III obese groups had pulse oximetry $\left(\mathrm{SpO}_{2}\right)$ during the night preceding the biopsy. The oxygen desaturation index, which is the number of oxygen desaturations (by $\geq 4 \%$ from the average saturations for the preceding $120 \mathrm{~s}$ that last $>10 \mathrm{~s}$ ) per $\mathrm{h}$ of study and second the proportion of the sleeping time spent below $\mathrm{SpO}_{2}$ of $90 \%$ (Table 1) were measured. The latter index was used to dichotomise the class III obese OHS vs non-OHS group (Table 1).

\section{Isolation of protein from human AT and WB for HIF1A}

The frozen AT specimens were homogenised in a urea/SDS buffer supplemented with Complete Protease Inhibitor (Roche Applied Science). Samples ( $80 \mu \mathrm{g}$ total protein) were run on a $7 \%$ acrylamide gel and western blotting (WB) was conducted as previously described [7]. Ten samples were run per gel with groups mixed. A rabbit anti-mouse HIF- $1 \alpha$ Primary antibody (10006421 Cayman) and HRPconjugated anti- $\beta$-actin (Abcam) was used for detection. Densitometry was performed using ImageJ, and the sample HIF1A abundance was corrected for actin. Due to technical difficulties of achieving high quality and quantifiable western blot images, samples had to be re-run on several occasion which led to sample depletion. For this reason the final number of successful quantifications was less than total participants. Gene expression in adipose tissue samples was determined as described [8].

\section{HIF1A in human primary adipocytes}

As a proof-of-concept study to observe the upregulation of HIF1A in response to hypoxia in adipocytes, primary

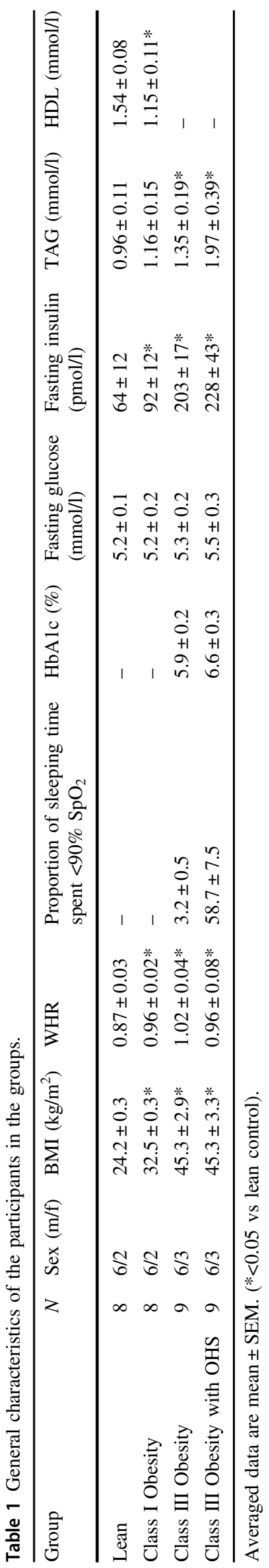


human preadipocytes were derived from subcutaneous abdominal AT and differentiated as described [9]. Fully differentiated adipocytes were exposed to normoxic or hypoxic conditions for $24 \mathrm{~h}$ in three separate hypoxia chambers ( $\mathrm{InVivO}_{2} 400$, Baker Ruskinn, UK) containing $0.1 \%, 1 \%$ or $5 \% \mathrm{O}_{2}$, all with $5 \% \mathrm{CO}_{2}$, while the control cells were cultured in a standard incubators $\left(21 \% \mathrm{O}_{2}\right.$ and $5 \% \mathrm{CO}_{2}$ ).

Whole-cell lysates were prepared in ice-cold Igepal lysis containing: $10 \mathrm{mM}$ Tris (pH 7.6), $0.25 \mathrm{M} \mathrm{NaCl}$ and $0.5 \%$ Igepal/NP-40. Each sample was loaded into an acrylamide gel along with a protein ladder (Thermo Scientific, UK). The same antibodies were used as for the tissue samples.

\section{Statistical analysis}

All data are presented as means \pm SEM unless otherwise stated. Differences were tested using an ANOVA test completed with a post hoc Bonferroni test. Statistical analyses were performed using the IBM SPSS Statistics software package (version 22). Statistical significance was considered as $p$-value $<0.05$.

\section{Results}

\section{HIF1A expression in human AT}

AT gene expression of HIFIA and hypoxia-sensitive genes were assessed in the four distinct groups: lean, class I, class III obese individuals with and without OHS. There were no statistically significant differences in HIFIA mRNA levels between lean, class I and class III obese individuals (Fig. 1A). However, HIFIA mRNA expression was higher in the class III obese subjects with OHS versus lean controls $(p=$ 0.02). AT HIF1A protein content showed a graded response between the groups with the highest abundance in the class III obese subjects with OHS, whereas the class I obese group showed no difference with lean participants (Fig. 1B, C). Class I obese individuals showed significantly higher fasting plasma insulin concentrations compared to lean controls $(p=0.03)$, but without change in fasting glucose levels (Table 1).

\section{Transcriptomic consequences of hypoxia activation in human AT}

There were no significant differences in expression of wellestablished hypoxia-sensitive genes, including HIFIA, GLUT1, VEGFA, PAII or ADIPOQ in AT biopsies between the four groups (Fig. 1A). However, there was a significantly higher expression of IL6 in the class III obese subjects with OHS versus lean $(p=0.04)$ and class I obese controls $(p=0.02)$, while $L E P$ was significantly higher in class III obese subjects compared to lean $(p=0.02)$ and class I obese controls ( $p=0.04$; Fig. 1A).

\section{Cellular markers of hypoxia in cultured human primary adipocytes}

Cellular HIF1A protein expression response to hypoxia $\left(0.1 \%, 1 \%\right.$ or $\left.5 \% \mathrm{O}_{2}\right)$ seemed graded where all hypoxic levels showed a response. However, again, the mRNA levels were paradoxical for HIF1A, very clear and consistent for a few direct HIF1A targets and mixed for other hypoxia-related targets indicating that the transcriptome is an unreliable read-out for hypoxia.

\section{Discussion}

AT hypoxia has been suggested as a possible cause of AT dysfunction in obesity and type 2 diabetes [10]. There is clear evidence that obesity in rodents results in hypoxic AT, as demonstrated by direct measurements of AT $\mathrm{PO}_{2}$ [11, 12]. Low $\mathrm{O}_{2}$ availability could potentially shift metabolic patterns towards glycolysis or lactate accumulation, but we did not observe this in a more recent study of whole body adipose tissue in vivo comparing lean and obese subjects [1]. However, studies in humans aiming at directly quantifying hypoxia or tissue $\mathrm{PO}_{2}$ resulted in conflicting data suggesting normoxia/hyperoxia [4] or hypoxia [3] in obese individuals. This discrepancy may be explained at least in part by heterogeneity in the study population as well as the different techniques used for the determination of hypoxia. In addition, these studies measured AT hypoxia/ $\mathrm{PO}_{2}$ in only one place in the tissue. Therefore, the possibility that hypoxic areas may exist in certain parts of the abdominal subcutaneous AT depot in obese subjects cannot be excluded.

The premise of our study is that HIF1A protein abundance in AT is a valid read-out for the presence of hypoxia. The stabilised HIF1A subunit regulates a well-defined network driving an adaptive cellular response to hypoxia [13]. HIF1A is arguably a natural definition of tissue hypoxia with its direct transcriptional regulation of metabolism and vascularisation.

We first measured AT expression of HIFIA at the mRNA level in all four groups, observing no significant differences between lean, class I and class III obese subjects. This is consistent with an earlier study comparing lean and obese individuals [14], but in contrast to data from Cancello et al. [15] who showed higher HIFIA mRNA expression in morbidly obese subjects versus lean controls. Neither of these studies provide any information on actual AT hypoxia whereas the design of our study was such that 
A

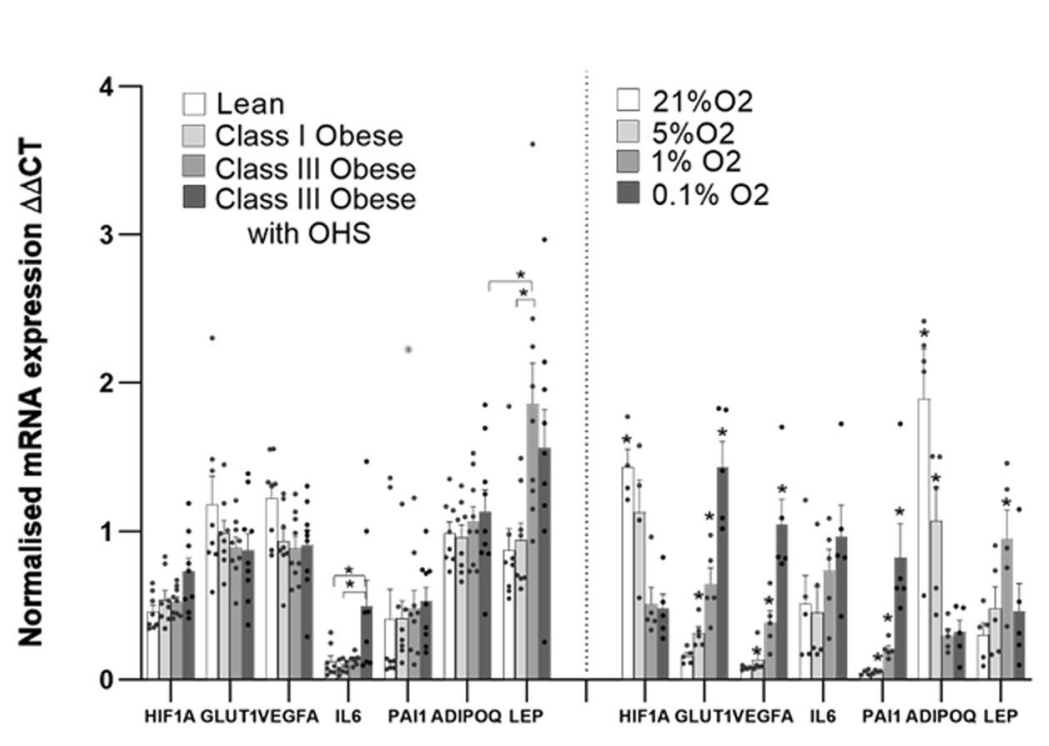

B

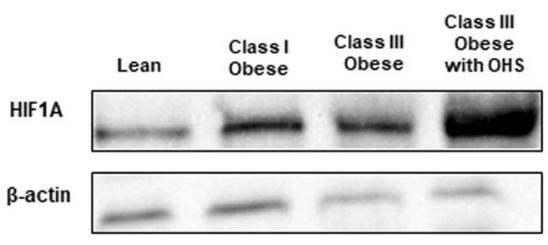

$\mathrm{C}$

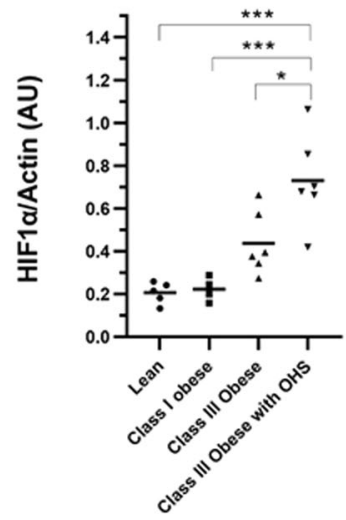

Fig. 1 HIF1A expression profiling. A mRNA expression of HIF1A, GLUT1, VEGFA, IL6, PAI1, ADIPOQ and LEP in AT from lean (mean $\mathrm{BMI}=24.2 \mathrm{~kg} / \mathrm{m}_{2}, n=8$ ), class I obese (mean BMI $=32.5 \mathrm{~kg} / \mathrm{m}_{2}, n=8$ ), class III obese (mean BMI $=45.3 \mathrm{~kg} / \mathrm{m}_{2}, n=9$ ), and class III obese with OHS (mean BMI $=45.3 \mathrm{~kg} / \mathrm{m}_{2}, n=9$ ) subjects was determined by real-time qPCR. Data are shown as $\Delta \Delta C \mathrm{~T}$ values (normalised to PPIA and UBC; mean \pm SEM). mRNA expression of HIF1A, GLUT1, VEGFA, IL6, PAI1, ADIPOQ and LEP in mature adipocytes after treatment with different $\mathrm{O} 2$ levels was determined by real-time qPCR. Data are shown as $\Delta \Delta \mathrm{CT}$ values (normalised to PGK1; $n=5$, mean \pm SEM). B Protein expression of HIF1A in the whole AT from lean $(n=5)$, class I obese $(n=4)$, class III obese $(n=6)$, and class III obese with obesity hypoventilation syndrome $(n=6)$ subjects was determined by western blot. C Protein densitometry of HIF1A in the four distinct phenotypes. Densitometry data were normalised to $\beta$-actin $(*<0.05$, $* *<0.001, * * *<0.0001)$.

we quantified systemic hypoxia in our class III obese subjects. Also, our in vitro studies of hypoxia in human adipocytes showed a paradoxical reduction in the HIFlA transcript whereas the downstream targets sometimes showed expected directional effects. This dissociation between transcript and protein is potentially explained by the stabilised HIF1A subunit indirectly promoting HIF1A mRNA degradation under sustained hypoxic conditions [16]. Consequently, HIFIA mRNA appears to poorly reflect actual hypoxia whereas the presence of HIF1A protein represents a valid marker.

The quantification of AT HIF1A protein abundance comparing lean and class I obese subjects showed no difference, despite class I obese having signs of metabolic dysregulation (significantly higher insulin resistance values and lower HDL). However, there was a clear increase in AT HIF1A protein abundance in class III obesity with actual hypoventilation and an intermediate response in class III obesity without hypoventilation.

In conclusion, these results argue that a genuine hypoxic response in AT is present in severe obesity, in particular if combined with systemic hypoxia (OHS), while it would not support the notion that a hypoxic response drives AT dysfunction at lower levels of obesity.

Acknowledgements This project was supported by the British Heart Foundation [RG/17/1/32663] and the Wellcome Trust (clinical research training fellowship to JMH: 104458/Z/14/Z). Prof Fredrik Karpe is the guarantor of this work and, as such, had full access to all the data in the study and takes responsibility for the integrity of the data and the accuracy of the data analysis.

Author contributions Conceptualisation by FK and JRS; methodology by MT, ARM, LA, ZM and JMH; investigation by MT, ARM, LA, $\mathrm{ZM}$, and JMH; writing - original draft by MT and FK; writing review \& editing by all authors.

\section{Compliance with ethical standards}

Conflict of interest The authors declare no competing interests.

Publisher's note Springer Nature remains neutral with regard to jurisdictional claims in published maps and institutional affiliations.

Open Access This article is licensed under a Creative Commons Attribution 4.0 International License, which permits use, sharing, adaptation, distribution and reproduction in any medium or format, as long as you 
give appropriate credit to the original author(s) and the source, provide a link to the Creative Commons license, and indicate if changes were made. The images or other third party material in this article are included in the article's Creative Commons license, unless indicated otherwise in a credit line to the material. If material is not included in the article's Creative Commons license and your intended use is not permitted by statutory regulation or exceeds the permitted use, you will need to obtain permission directly from the copyright holder. To view a copy of this license, visit http://creativecommons.org/licenses/by/4.0/.

\section{References}

1. Hodson L, Humphreys SM, Karpe F, Frayn KN. Metabolic signatures of human adipose tissue hypoxia in obesity. Diabetes 2013;62:1417-25.

2. Seo JB, Riopel M, Cabrates P, Huh JH, Bandyopadhyay GK, Andreyev AY, et al. Knockdown of ANT2 reduces adipocyte hypoxia and improves insulin resistance in obesity. Nat Metab 2019;1:86-97.

3. Pasarica M, Sereda OR, Redman LM, Albarado DC, Hymel DT, Roan LE, et al. Reduced adipose tissue oxygenation in human obesity: evidence for rarefaction, macrophage chemotaxis, and inflammation without an angiogenic response. Diabetes 2009;58:718-25.

4. Goossens GH, Bizzarri A, Venteclef N, Essers Y, Cleutjens JP, Konings $\mathrm{E}$, et al. Increased adipose tissue oxygen tension in obese compared with lean men is accompanied by insulin resistance, impaired adipose tissue capillarization, and inflammation. Circulation 2011;124:67-76.

5. Karpe F, Vasan SK, Humphreys SM, Miller J, Cheeseman J, Dennis AL, et al. Cohort Profile: The Oxford Biobank. Int J Epidemiol. 2018;47:21-g.

6. Manuel AR, Hart N, Stradling JR. Correlates of obesity-related chronic ventilatory failure. BMJ Open Respir Res. 2016;3:e00110.
7. Michailidou Z, Turban S, Miller E, Zou X, Schrader J, Ratcliffe $\mathrm{PJ}$, et al. Increased angiogenesis protects against adipose hypoxia and fibrosis in metabolic disease-resistant 11beta-hydroxysteroid dehydrogenase type 1 (HSD1)-deficient mice. J Biol Chem. 2012;287:4188-97.

8. Neville MJ, Collins JM, Gloyn AL, McCarthy MI, Karpe F. Comprehensive human adipose tissue mRNA and microRNA endogenous control selection for quantitative real-time-PCR normalization. Obesity. 2011;19:888-92.

9. Todorcevic M, Hilton C, McNeil C, Christodoulides C, Hodson L, Karpe F, et al. A cellular model for the investigation of depot specific human adipocyte biology. Adipocyte. 2017;6:40-55.

10. Trayhurn P. Hypoxia and adipose tissue function and dysfunction in obesity. Physiol Rev. 2013;93:1-21.

11. Rausch ME, Weisberg S, Vardhana P, Tortoriello DV. Obesity in $\mathrm{C} 57 \mathrm{BL} / 6 \mathrm{~J}$ mice is characterized by adipose tissue hypoxia and cytotoxic T-cell infiltration. Int J Obes. 2008;32:451-63.

12. Ye J, Gao Z, Yin J, He Q. Hypoxia is a potential risk factor for chronic inflammation and adiponectin reduction in adipose tissue of ob/ob and dietary obese mice. Am J Physiol Endocrinol Metab. 2007;293:E1118-28.

13. Semenza GL. Hypoxia-inducible factor 1: master regulator of $\mathrm{O} 2$ homeostasis. Curr Opin Genet Dev. 1998;8:588-94.

14. Poulain-Godefroy O, Lecoeur C, Pattou F, Fruhbeck G, Froguel P. Inflammation is associated with a decrease of lipogenic factors in omental fat in women. Am J Physiol Regul Integr Comp Physiol. 2008;295:R1-7.

15. Cancello R, Henegar C, Viguerie N, Taleb S, Poitou C, Rouault C, et al. Reduction of macrophage infiltration and chemoattractant gene expression changes in white adipose tissue of morbidly obese subjects after surgery-induced weight loss. Diabetes. 2005;54:2277-86.

16. Galban S, Gorospe M. Factors interacting with HIF-1alpha mRNA: novel therapeutic targets. Curr Pharm Des. 2009; 15:3853-60. 